Planta (1995) 195:505-513

\title{
Responses to iron deficiency in Arabidopsis thaliana: The Turbo iron reductase does not depend on the formation of root hairs and transfer cells
}

\author{
Petra R. Moog ${ }^{1 *}$, Tom A. W. van der Kooij ${ }^{1}$, Wolfgang Brüggemann ${ }^{2}$, John W. Schiefelbein ${ }^{3}$, Pieter J. C. Kuiper ${ }^{1}$ \\ ${ }^{1}$ Department of Plant Physiology, Biological Center, University of Groningen, POB 14, 9750 AA Haren (Gn.), The Netherlands \\ ${ }^{2}$ Department of Ecological Plant Physiology, Heinrich-Heine-University, Universitätsstrasse 1, D-40225 Düsseldorf, Germany \\ ${ }^{3}$ Department of Biology, University of Michigan, Ann Arbor, MI 48109, USA \\ Received: 26 April 1994 / Accepted: 25 July 1994
}

\begin{abstract}
Arabidopsis thaliana (L.) Heynh. Columbia wild type and a root hair-less mutant RM57 were grown on iron-containing and iron-deficient nutrient solutions. In both genotypes, ferric chelate reductase (FCR) of intact roots was induced upon iron deficiency and followed a Michaelis-Menten kinetic with a $K_{\mathrm{m}}$ of 45 and $54 \mu \mathrm{M}$ $\mathrm{Fe}^{\mathrm{III}}$-EDTA and a $V_{\max }$ of 42 and $33 \mathrm{nmol} \mathrm{Fe}^{2+} \cdot(\mathrm{g}$ $\mathrm{FW}^{-1} \cdot \mathrm{min}^{-1}$ for the wild type and the mutant, respectively. The $\mathrm{pH}$ optimum for the reaction was around $\mathrm{pH}$ 5.5. The approximately four fold stimulation of FCR activity was independent of formation of root hairs and/or transfer cells induced by iron deficiency. Iron-deficiencyinduced chlorosis and the development of a rigid root habit disappeared when ferric chelate was applied to the leaves, while FCR activity remained unchanged. The time course of the responses to iron deficiency showed that morphological and physiological responses were controlled separately.
\end{abstract}

Key words: Arabidopsis - Ferric chelate reductase - Root hair - Transfer cell

\section{Introduction}

Iron deficiency causes a number of visible symptoms in plants, such as severe chlorosis (Abadia 1992) and changes in the morphology of the roots (Römheld and Marschner 1981), enhanced formation of root hairs (Römheld 1987) and the development of transfer cells in the root apical zones (Landsberg 1982, 1986, 1989; Römheld and Kramer 1983). In the same root zones, iron deficiency enhanced proton extrusion and induced the so-called "Turbo reductase" system (Bienfait 1988), a de-

\footnotetext{
* Present address: Department of Ecological Plant Physiology, Heinrich-Heine-University, Universitätsstrasse 1, D-40225 Düsseldorf, Germany

Abbreviations: $\mathrm{FCR}=$ ferric chelate reductase; $\mathrm{FW}=$ fresh weight

Correspondence to: Petra R. Moog; FAX: 49 (211) 3113085
}

scription which comes from the enhancement of the reduction of external ferric compounds by intact roots. This reducing capacity (in vivo activity) has been identified as the enhanced activity of a plasma-membranebound ferric chelate reductase (FCR; for review, see Moog and Brüggemann 1994).

The coincidence of morphological and physiological responses to iron deficiency in the apical root zone has led to the assumption that the enhanced FCR activity is localized in root hairs and the plasma membrane (PM) of transfer cells. This interpretation was reinforced by the observation that young root hairs in particular had a very high ferric iron/ferricyanide reductase activity, as measured by the formation of Prussian Blue (Bell et al. 1988). However, no direct evidence has been presented so far for the obligatory involvement of root hairs and transfer cells in physiological responses to iron deficiency. Doubts about this came from the knowledge that increased root hair formation has also been observed upon deficiency of oxygen (Moog and Janiesch 1990) and of phosphate, where these root hairs show no increased FCR activity (Bell et al. 1988; Misra et al. 1988). In contrast to earlier studies (Bell et al. 1988), Chaney et al. (1992) observed that enhanced root hair formation of iron-deficient tomato plants followed the development of chlorosis in the leaves. Using different grades of iron deficiency, the authors found that even under mild iron-deficiency stress, when only little root hair formation was visible by eye, FCR activity was slightly enhanced over control values. However, these data were not very conclusive, since tomato roots develop normal root hairs also when grown under iron-sufficient conditions in nutrient solution and when examined by light microscopy (own observations). Although no chronological comparison of enhanced FCR activity with enhanced root hair formation was made in their study, Chaney et al. (1992) questioned the role of enhanced root hair formation in iron uptake. In the present study we have tried to clarify this matter by comparing the responses of wild-type Arabidopsis thaliana Columbia and the mutant RM57 to iron deficiency. The latter is a root hair-free mutant, 
which was recently identified (Schiefelbein and Somerville 1990), and thus provides a good opportunity to see if enhanced FCR activity (Turbo reductase) depends on root hairs. We also examined the actively reducing zone of the roots of mutant plants for transfer-cell formation during iron deficiency.

The second aim of the present investigation was to study the time course of morphological and physiological responses of shoots and roots to iron deficiency in the root medium. It was the intention that this analysis should give information about possible correlations of the induction of enhanced FCR activity with morphological responses. Third, the influence of foliar ferric-chelate application on iron-deficient plants was studied for morphological and physiological responses in order to identify possible shoot-root interaction.

\section{Materials and methods}

Plant material. The mutant line (RM57) was derived from the Columbia ecotype of Arabidopsis thaliana (L.) Heynh. It was recovered from a population of ethyl-methanesulfate-treated plants, as previously described (Schiefelbein and Somerville 1990). The roots of the RM57 plants are essentially hairless, and this phenotype has been maintained through four selfing generations of this line.

Plants of A. thaliana Columbia (wild type) and mutant RM57 were grown by a method modified from that used by Doddema (1978): seeds were germinated in closed Petri dishes containing $45 \mathrm{~g}$ Perlite (Agriperl, Dortmund, Germany and $23.5 \mathrm{ml}$ nutrient solution. The nutrient solutions consisted of $2.0 \mathrm{mM} \mathrm{KH}_{2} \mathrm{PO}_{4}, 0.5 \mathrm{mM}$ $\mathrm{K}_{2} \mathrm{HPO}_{4}, 1.5 \mathrm{mM} \mathrm{NH}_{4} \mathrm{NO}_{3}, 1 \mathrm{mM} \quad \mathrm{MgSO}_{4}, 0.85 \mathrm{mM} \mathrm{CaCO}$, $0.07 \mathrm{mM} \mathrm{H}_{3} \mathrm{BO}_{3}, 0.014 \mathrm{mM} \mathrm{MnCl}, 0.001 \mathrm{mM} \mathrm{ZnSO}, 0.005 \mathrm{mM}$ $\mathrm{CuSO}_{4}, 0.0002 \mathrm{mM} \mathrm{MoO}$ and $0.05 \mathrm{mM} \mathrm{Na}-\mathrm{Fe}(\mathrm{III})$-EDTA, adjusted to $\mathrm{pH} 6.8$ with $\mathrm{KOH}$. To ensure an even germination and the formation of slightly etiolated plants, the Petri dishes were illuminated continuously for $24 \mathrm{~h}$ with fluorescent tubes $(120 \mu \mathrm{mol}$ quan$\mathrm{ta} \cdot \mathrm{m}^{-2} \cdot \mathrm{s}^{-1}$; TL-33 lamps; Philips, Eindhoven, The Netherlands) in climate chambers, at $25^{\circ} \mathrm{C}$ and $90 \%$ relative humidity, and then placed in darkness for another $24 \mathrm{~h}$. Subsequently, the Petri dishes were transferred to short-day conditions ( $8 \mathrm{~h}$ light per day) to postpone flowering of the plants. After $4 \mathrm{~d}$, when plants were in the four-leaf stage (approx. $3 \mathrm{~mm}$ diameter), seedlings were carefully removed from the Perlite and transferred to aerated nutrient solution. Seedlings were allowed to float on the nutrient solutions, using styropor discs of $1.5 \mathrm{~cm}$ diameter and $0.3 \mathrm{~cm}$ thickness. To prevent growth of algae in the nutrient solution, the space between the floating plants was filled with small black spheres of polyethylene. When plants were in the six-leaf stage $(10 \mathrm{~d}$ old $)$, they were transferred to regular waterculture equipment with aerated nutrient solution with or without iron. The nutrient solutions were replaced every $2-3 \mathrm{~d}$ and the $\mathrm{pH}$ was adjusted daily. In some experiments, $50 \mu \mathrm{M} \mathrm{Fe}(\mathrm{III})-\mathrm{EDTA}$ ( $\mathrm{pH} 6.5$ ) was carefully applied twice a day on chlorotic leaves with a small paintbrush.

Morphological changes upon iron-deficiency treatments were protocolled daily. This included observation of root hair formation by light microscopy.

Ferric-chelate reductase activity was measured as in-vivo reduction of Fe(III)-EDTA by intact plant roots. In the procedure, originally described by Chaney et al. (1972), the formation of the red Fe(II)bathophenanthrolinedisulphonate complex was followed by measuring its absorption at $535 \mathrm{~nm}$. In general, the reaction was performed in aluminium-foil-wrapped glass vials for 15-30 min with $0.3 \mathrm{mM}$ bathophenanthrolinedisulphonic acid and $0.2 \mathrm{mM} \mathrm{Fe}$ (III)EDTA in otherwise full-strength nutrient solution, buffered with $10 \mathrm{mM}$ Mes-KOH of $\mathrm{pH} \mathrm{5.5.} \mathrm{Control} \mathrm{samples} \mathrm{contained} \mathrm{no} \mathrm{iron}$ chelate during the incubation period; Fe(III)-EDTA was added to the control vials after removal of the plants. The absorption of blanks without plants was subtracted from the measured values in order to correct for photoreduction of bathophenanthrolinedisulphonic acid.

To identify the root regions with enhanced FCR activity, roots of intact plants were embedded in Petri dishes containing the same reaction mixture and $0.75 \%$ agar-agar at $35-40^{\circ} \mathrm{C}$ and were left in the dark for 15-30 min (Marschner et al. 1986).

Electron microscopy. Root tips were cut at the elongation zone, approx. $5 \mathrm{~mm}$ above the tip. This region exhibited the highest FCR activity as identified by the agar-embedding technique described above. Samples were first washed with tap water for 2-3 min, followed by a wash with $0.1 \mathrm{M}$ sodium cacodylate buffer at $\mathrm{pH} 7.2$ (buffer A), and then fixed for $1 \mathrm{~h}$ with $3 \%$ glutaraldehyde in buffer A. After washing in buffer and postfixation in $1 \%$ osmium tetroxide in buffer A, samples were stained overnight with $1 \%$ uranyl-acetate, dehydrated in a graded series of ethanol and embedded in Epon 812 . Sections were-double stained with $2 \%$ aqueous uranyl acetate followed by lead citrate (Reynold 1963) and examined in a Philips 301 electron microscope.

Sampling. Three independent series of experiments were carried out each with four individual plants. Each series was carried out on plants at exactly the same point in their life cycle and daily applications of ferric chelate, measurements and observations were always made on the same hour of the day. Similar results were obtained in all three series. Mean values and standard errors of one representative experiment each are given in the figures

\section{Results}

Culture conditions and biomass development. To investigate in-vivo reduction capacity of intact $A$. thaliana roots, plants were grown on nutrient solution by using the floating-styropor-disc technique (see Materials and methods). The wild type showed a linear increase in biomass in both treatments (Fig. 1). Iron-deficient plants grew somewhat slower than control plants and developed the iron-deficiency chlorosis, but kept on growing and even flowered under iron-deficient conditions. For further details on iron-deficiency chlorosis see section on

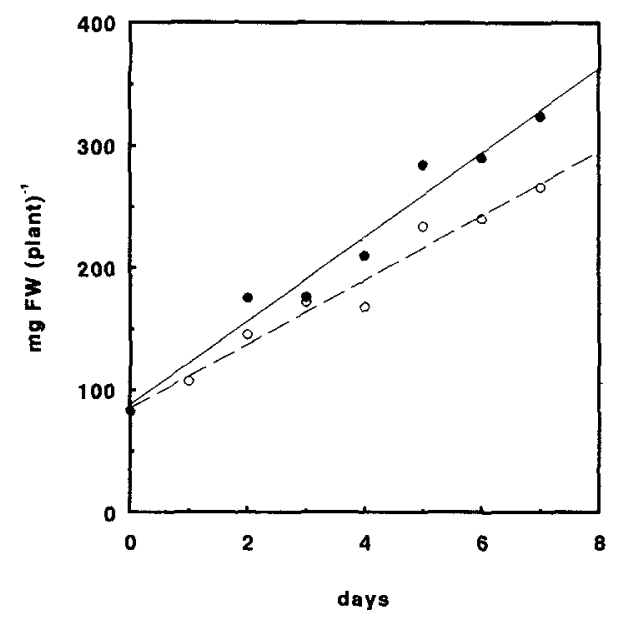

Fig. 1. Effect of iron deficiency on biomass development of $A$. thaliana $\mathrm{cv}$. Columbia wild type growing on iron-deficient (--O--) and iron-sufficient $(-\bullet)$ nutrient solution. Data are mean values of a single experiment with four replicates; similiar results were obtained in two other independent experiments 


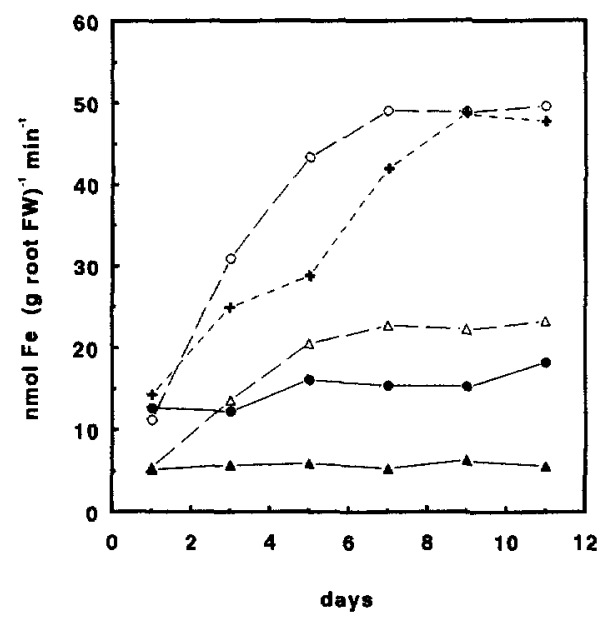

Fig. 2. In-vivo FCR activity as a response of different iron nutrition. $0, \bullet,+, A$. thaliana $\mathrm{cv}$. Columbia wildtype; $\Delta, \Delta A$. thaliana root hair-less mutant RM57; - - - - - - nutrient solution contained $50 \mu \mathrm{M} \mathrm{Fe} \mathrm{F}^{3+}$-EDTA (controls); --O--, -- --- , iron-deficient nutrient solution; -- +--, iron-deficient nutrient solution, but $50 \mu \mathrm{M}$ $\mathrm{Fe}^{3+}$-EDTA was applied to the leaves twice a day

morphological responses. For the mutant a similar biomass development was found (data not shown).

Induction of in-vivo $F C R$. Under iron-deficient conditions in-vivo FCR activity (calculated per $\mathrm{g}$ root $\mathrm{FW}$ ) of $A$. thaliana Columbia wild type was increased as shown in Table 1. The 3.8-fold stimulation of the reduction capacity on a fresh weight basis was not the result of decreased growth (see Fig. 1). Under iron-deficient conditions, invivo FCR activity of the root hair-less mutant increased in the same order of magnitude as the wild type. On a fresh weight basis, reduction rates of the mutant were always lower than those of the wild type, but the physiological reponse to iron-deficient solution was the same in both genotypes. The rise in FCR activity, induced by iron deficiency was, therefore, independent of the presence of root hairs.

The time course of the induction of FCR activity in intact roots is shown in Fig. 2. Iron-sufficient-grown $A$. thaliana wild type did not show any change in reduction rates during the experiment. In contrast, in-vivo activity of iron-deficient roots had already increased on the third day of the omission of iron from the nutrient solution. In all series, highest activities were found after days 5-7 of iron depletion. The same time course was found for the root hair-less mutant RM57; again reduction rates were lower than in the wild type, both in the iron-deficient and in iron-sufficient plants (cf. Table 1). Roots of wild-type plants, which were grown on iron-deficient medium, but received ferric chelate twice a day via the leaves, showed rates of FCR activity similar to those plants which were grown without iron in the nutrient solution. Iron application to the leaves prevented chlorosis (not shown).

Kinetics of ferric reduction. In-vivo FCR activity of the wild type depended on the iron-chelate concentration and followed a Michaelis-Menten kinetic with a $K_{\mathrm{m}}$ of $45 \mu \mathrm{M} \mathrm{Fe}^{\mathrm{III}}$-EDTA and a $V_{\max }$ of $42 \mathrm{nmol} \mathrm{Fe}^{2+} \cdot(\mathrm{g}$ $\mathrm{FW})^{-1} \cdot \mathrm{min}^{-1}$ (Fig. 3). For the mutant, a $K_{\mathrm{m}}$ of $54 \mu \mathrm{M}$
Table 1. Ferric-chelate reductase Activity of intact roots of Arabidopsis thaliana Columbia wild type and the root hair-less mutant RM57 after $7 \mathrm{~d}$ of growth on iron-deficient $(-\mathrm{Fe})$ and iron-sufficient $(+\mathrm{Fe})$ nutrient solution. In-vivo activity is given in $\mathrm{nmol}$ $\mathrm{Fe} \cdot(\mathrm{g} \text { root } \mathrm{FW})^{-1} \cdot \min ^{-1} ; n=4$, mean $\pm \mathrm{SE}$

\begin{tabular}{lrrll}
\hline A. thaliana genotype & $+\mathrm{Fe}$ & $-\mathrm{Fe}$ & $\begin{array}{l}\text { Stimulation- } \\
\text { fold }\end{array}$ \\
\hline Columbia wild type & $14.5 \pm 1.9$ & $54.5 \pm 8.3$ & $3.8 \cdot$ \\
Hair-less mutant RM57 & $5.4 \pm 0.9$ & $22.8 \pm 3.4$ & 4.2 \\
\hline
\end{tabular}

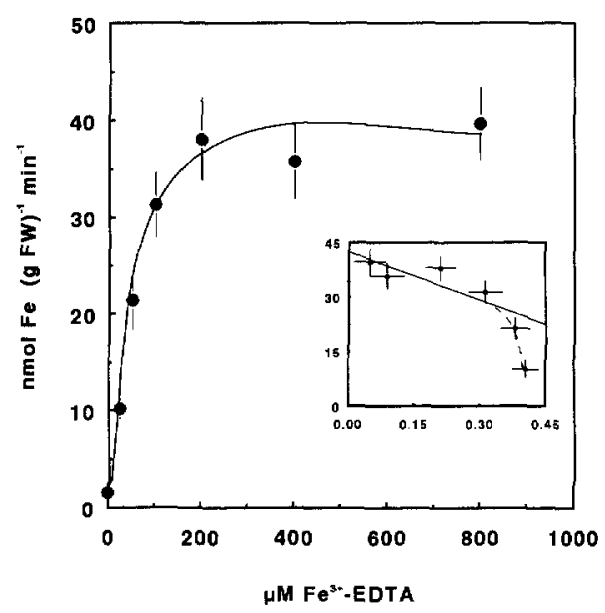

Fig. 3. Effect of $\mathrm{Fe}^{3+}$-EDTA concentration on $\mathrm{Fe}^{3+}$-EDTA reduction by intact iron-deficient $A$. thaliana cv. Columbia wild-type roots. Insert: Eadie-Hofstee plot of original data. The solid fitted line for the concentration range from 50 to $800 \mu \mathrm{M} \mathrm{Fe}^{3+}$-EDTA was used for calculations of $V_{\max }\left[42 \mathrm{nmol} \mathrm{Fe} \mathrm{e}^{2+} \cdot(\mathrm{g} \mathrm{FW})^{-1} \cdot \mathrm{min}^{-1}\right]$ and $K_{m}\left(45 \mu \mathrm{M} \mathrm{Fe}{ }^{3+}-\right.$ EDTA $)$

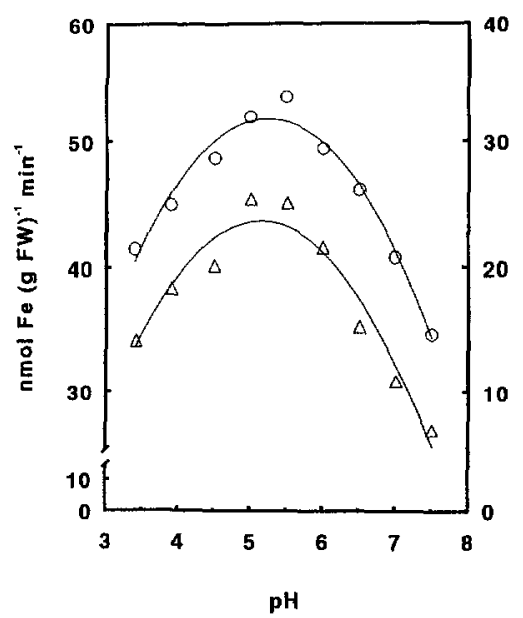

Fig. 4. The pH-dependence of in-vivo FCR activity by iron-deficient intact $A$. thaliana roots. O, left y-axis, cv. Columbia wild type; $\triangle$, right y-axis, root hair-less mutant RM 57

$\mathrm{Fe}^{\mathrm{III}}$-EDTA and a $V_{\max }$ of $33 \mathrm{nmol} \mathrm{Fe} \mathrm{n}^{2+} \cdot(\mathrm{g} \mathrm{FW})^{-1} \cdot \mathrm{min}^{-1}$ were calculated.

The $\mathrm{pH}$ dependence of in vivo FCR activity is shown in Fig. 4. For both genotypes a $\mathrm{pH}$ curve of an enzymatically-driven process with identical optima was found. 
A

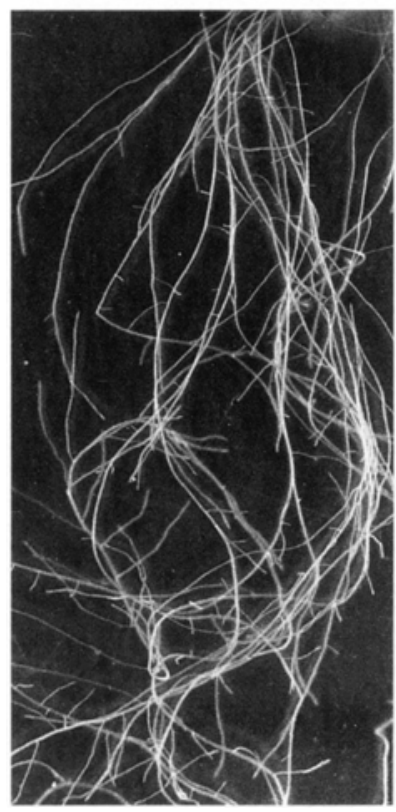

B

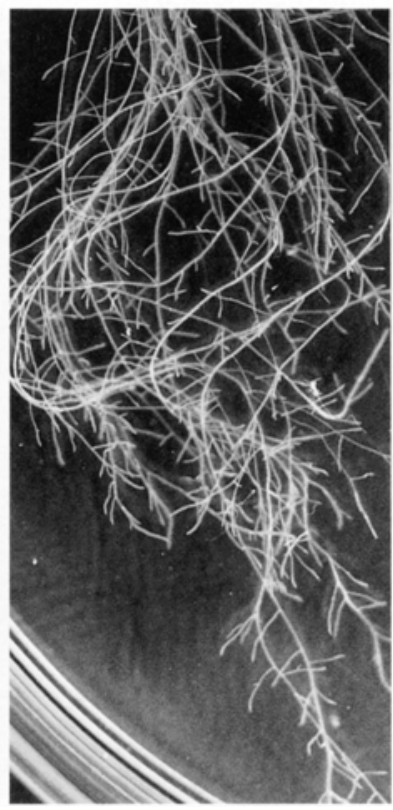

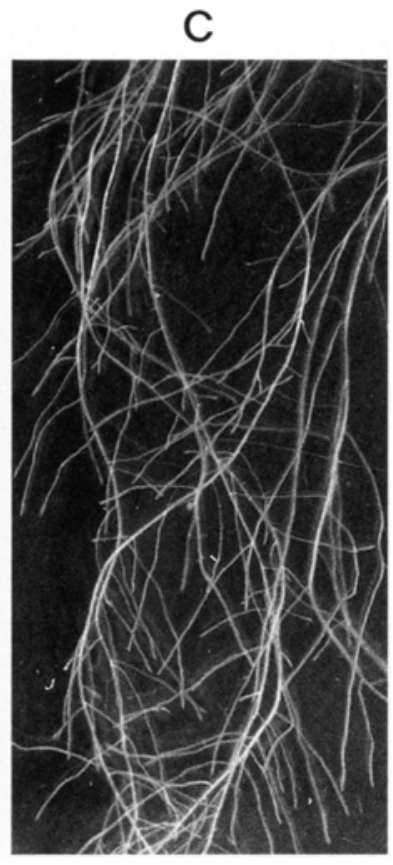

Fig. 5A-C. Root morphology of $A$. thaliana $\mathrm{cv}$. Columbia wildtype after a 12-d treatment with different iron supplies. A plants grown in iron-sufficient nutrient solution; $\mathbf{B}$ plants grown in iron-deficient nutrient solution; $\mathbf{C}$ plants grown in iron-deficient nutrient solution, leaves were treated with ferric chelate twice a day
The pH optimum of FCR activity of intact Arabidopsis roots was in the range of the assumed apoplasmic $\mathrm{pH}$, at 5.0-5.5. The comparison of the kinetic data revealed no further difference between the two genotypes.

Localization of FCR activity. As a first step in the identification of specialized root cells showing enhanced FCR activity, the agar-embedding technique was used for both genotypes under iron-sufficient and iron-deficient conditions. There was no difference in the response between the root hair-less mutant and the wild type: under ironsufficient conditions the agar close to the root surface was only slightly reddish, while in iron-deficient roots it turned bright red. The rise of activity was independent of the existence of root hairs, it occurred only around the youngest root parts showing the highest intensity around the elongation and maturation zones, approx. $3-5 \mathrm{~mm}$ behind the root tips.

Morphological responses to iron deficiency. Already after $24 \mathrm{~h}$ of iron deficiency, root-hair formation of the wild type was strongly increased and was apparent during the whole observation period (i.e. $11 \mathrm{~d}$ ). Highest FCR activity took place much later than the initiation of increased root hair formation, i.e. between days 5 and 7 (cf. Fig. 2). From day 5 on, the overall root habit of iron-deficient plants was changed, when compared to iron-sufficient plants. Lateral roots developed under iron deficiency were shorter, and from days 6-7 on, both lateral root length and interlateral distance was decreased. From day 8 on, lateral roots also occurred in the first centimeter behind the root tip, and the root habit changed into a rigid and highly branched form by days $10-11$. Iron deficiency did not influence the length of the four to five main roots of each plant, but the length of the laterals was decreased. The number of lateral roots per centimeter of main root and, especially, the number of laterals in the

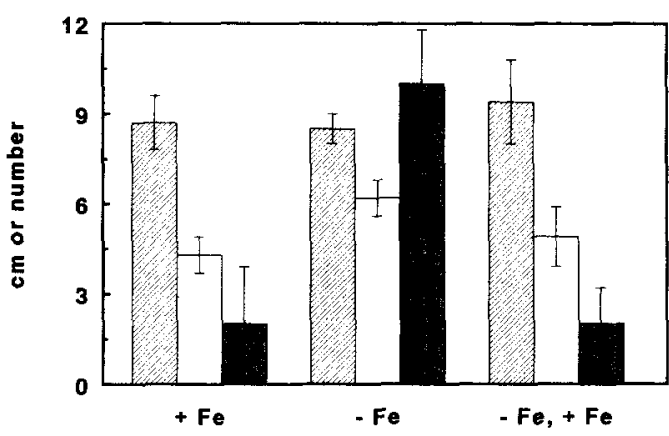

Fig. 6. Effect of iron deficiency on parameters of root growth of $A$. thaliana $\mathrm{cv}$. Columbia wildtype: + Fe, nutrient solution contained $50 \mu \mathrm{M} \mathrm{Fe}^{3+}$-EDTA iron (control plants); - Fe, iron-deficient nutrient solution; $-\mathrm{Fe},+\mathrm{Fe}$, iron-deficient nutrient solution, but $50 \mu \mathrm{M}$ $\mathrm{Fe}^{3+}$-EDTA were applied to the leaves twice a day; $n=4$, mean \pm SE. $\square$, number of lateral roots (cm root tip) $)^{-1}$

first centimeter behind the root tip, were significantly increased compared to roots grown under iron-sufficient conditions (Figs. 5, 6).

During the iron-deficiency treatment, first chlorosis was observed at the youngest center leaves (day 2), and from day 5 on mature leaves also showed chlorosis. Chlorosis increased regularly from slight green to light yellow. At day 11, young leaves turned light yellow with white spots. Except for the increased root hair formation of the wild type, no further differences in the response pattern between mutant and wild type were found.

Plants, which had developed severe chlorosis after growth on iron-deficient medium for $8 \mathrm{~d}$, recovered when ferric chelate was applied to the leaves. Recovery began during the first day after foliar application when the youngest leaves in the center of the rosette turned green again and by day 11 the older leaves had regreened also. 


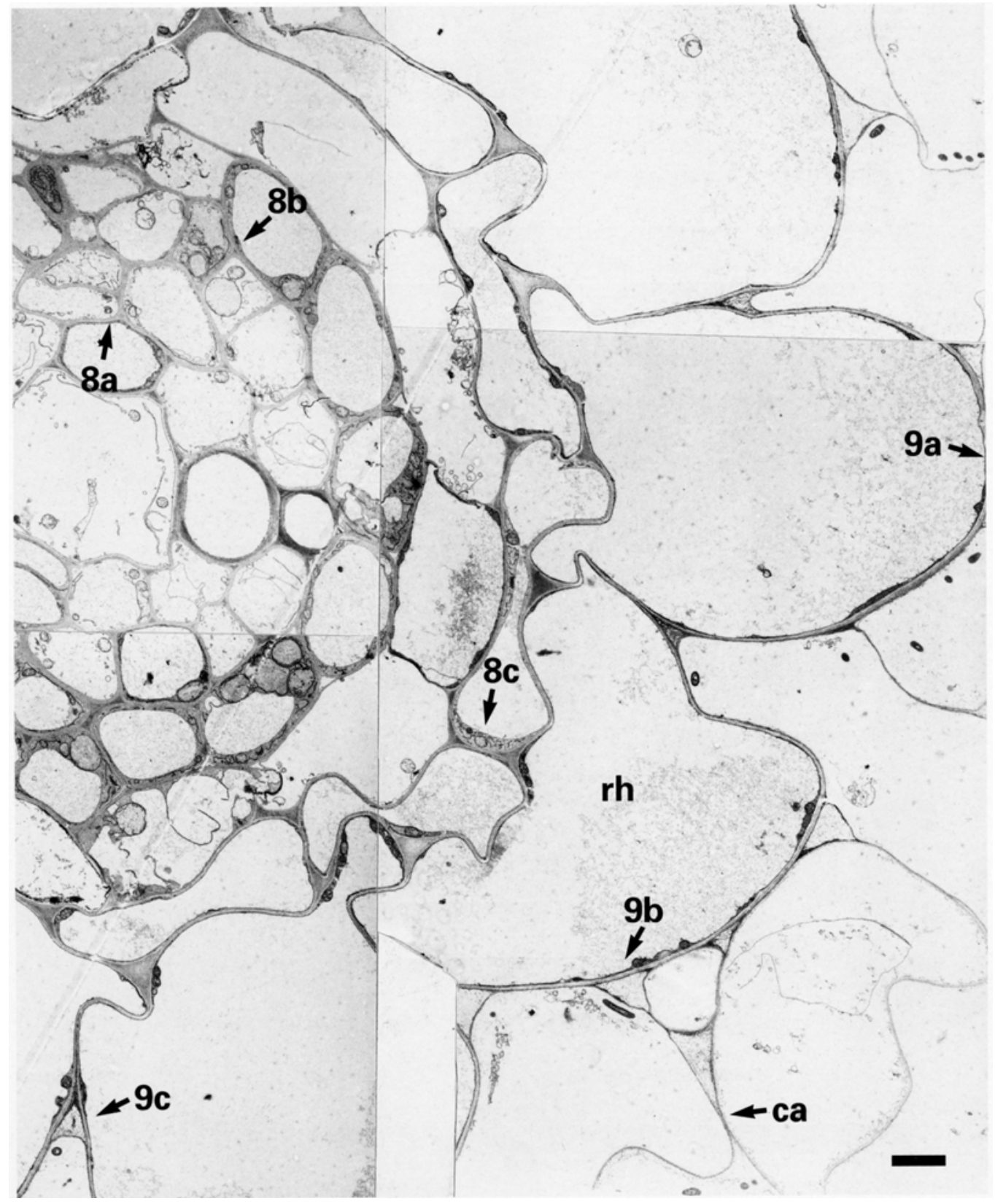

Fig. 7. Electron micrograph of a cross-section of an irondeficient root of $A$. thaliana mutant RM57 about $5 \mathrm{~mm}$ behind the apex. No root hairs were found. Arrows indicate positions of enlargements shown in Figs. 8A-C and 9A-C. $r h$, rhizodermal cell; ca, remnants of calyptra. $\times 2800 ;$ bar $=3 \mu \mathrm{m}$
In these plants, the rigid root habit disappeared within $2-3 \mathrm{~d}$, and both lateral root length and the interlateral distance were like those of the iron-sufficient plants by days 10-11. Plants which had been grown on iron-deficient medium, but received ferric chelate by foliar application from the beginning of the treatment on, did not develop the symptoms described above. Shoots and roots were similar to those of the iron-sufficient plants, although the leaves appeared somewhat lighter.

Electron microscopy. Root sections of the elongation and maturation zones were examined by electron microscopy to test wether the root hair-less mutant RM57 developed transfer cells when grown on iron-deficient medium. According to Kramer et al. (1980) and Landsberg (1986) a typical rhizodermal transfer cell induced by iron deficien- cy has dense cytoplasm and labyrinthine cell wall protuberances into the cytoplasm.

Figure 7 shows part of a cross section of an iron-deficient $A$. thaliana RM57 mutant. No root hairs were found in any of the sections examined. The rhizodermal cells were highly vacuolated, but this was not due to iron deficiency, because iron-fed controls showed the same structure (not shown). Around the rhizodermal cells, remnants of the calyptra could be seen. Enlargements of the micrographs of cell walls and plasma membranes of the different cell types clearly showed a regular formation cell walls and plasma membranes, without any loops or cell wall ingrowths. No other surface extensions of the plasma membrane could be observed. Cell wall labyrinths were found neither in cortical and other cells inside the root (Fig. 8a, b, c) nor in those cells which were in direct 

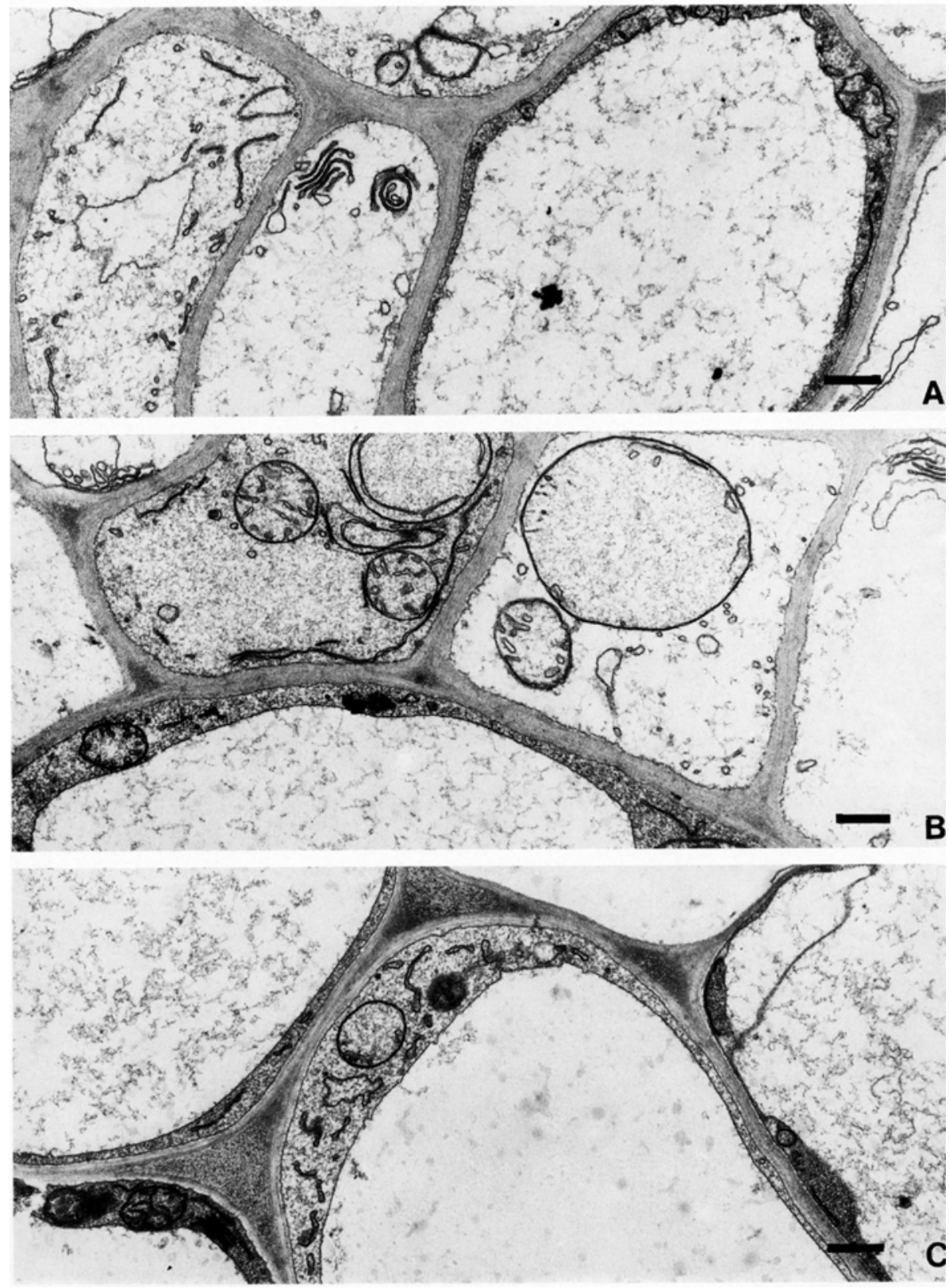

Fig. 8A-C. Different cell types from the inner (A), medium (B) and outer (C) layers of the central tissue of the irondeficient RM 57 root depicted in Fig. 7. $\times 15908 ; \operatorname{bar}(\mathrm{s})=0.5 \mu \mathrm{m}$ contact with the external medium (Fig. 9a, b, c). Screening of all cross-sections failed to reveal the presence of any transfer cell. Also, no morphological differences could be found in cross-sections of the same region of roots grown with an iron supply. The expression of enhanced FCR activity in the hair-less mutant seems to be independent of the genesis of rhizodermal transfer cells.

\section{Discussion}

The in-vivo reduction rate of intact roots of $A$. thaliana of approx. $55 \mathrm{nmol} \mathrm{Fe} \cdot \mathrm{min}^{-1} \cdot(\mathrm{g} \mathrm{FW})^{-1}$ and the four fold stimulation of its activity after exposure of the roots to an iron-deficient medium agree with data from other species: the reductase activity of iron-deficient Phaseolus vulgaris was $\left.67 \mathrm{nmol} \mathrm{Fe} \cdot \mathrm{min}^{-1} \cdot \mathrm{g} \mathrm{FW}\right)^{-1}$ (Sijmons and Bien- fait 1983) and Lycopersicon esculentum also showed a four fold stimulation of its activity during iron deficiency (Bienfait 1987). The absolute reduction rates strongly depend on the species tested: the rates for iron-deficient plants range from $0.29 \mathrm{nmol} \mathrm{Fe} \cdot \mathrm{min}^{-1} \cdot(\mathrm{g} \mathrm{FW})^{-1}(C y d o-$ nia oblongata, Dolcet-Sanjuan et al. 1992) to $107 \mathrm{nmol}$ $\mathrm{Fe} \cdot \mathrm{min}^{-1},(\mathrm{~g} \mathrm{FW})^{-1}$ (Lycopersicon esculentum, Buckhout et al. 1989) and they exhibit stimulations ranging from 1.7-fold (Plantago lanceolata, Schmidt et al. 1990) to 22.4fold (Solanum tuberosum, Bienfait 1987). In addition to a true effect of species in the response to iron deficiency, this large variation may be caused partly because the reduction rates are calculated per gram fresh weight. If elongation and maturation zones are the major sites of reduction, the bulk root size and weight strongly influence the above calculation without contributing much to the actual ferric-reduction activity. Only a few measure- 

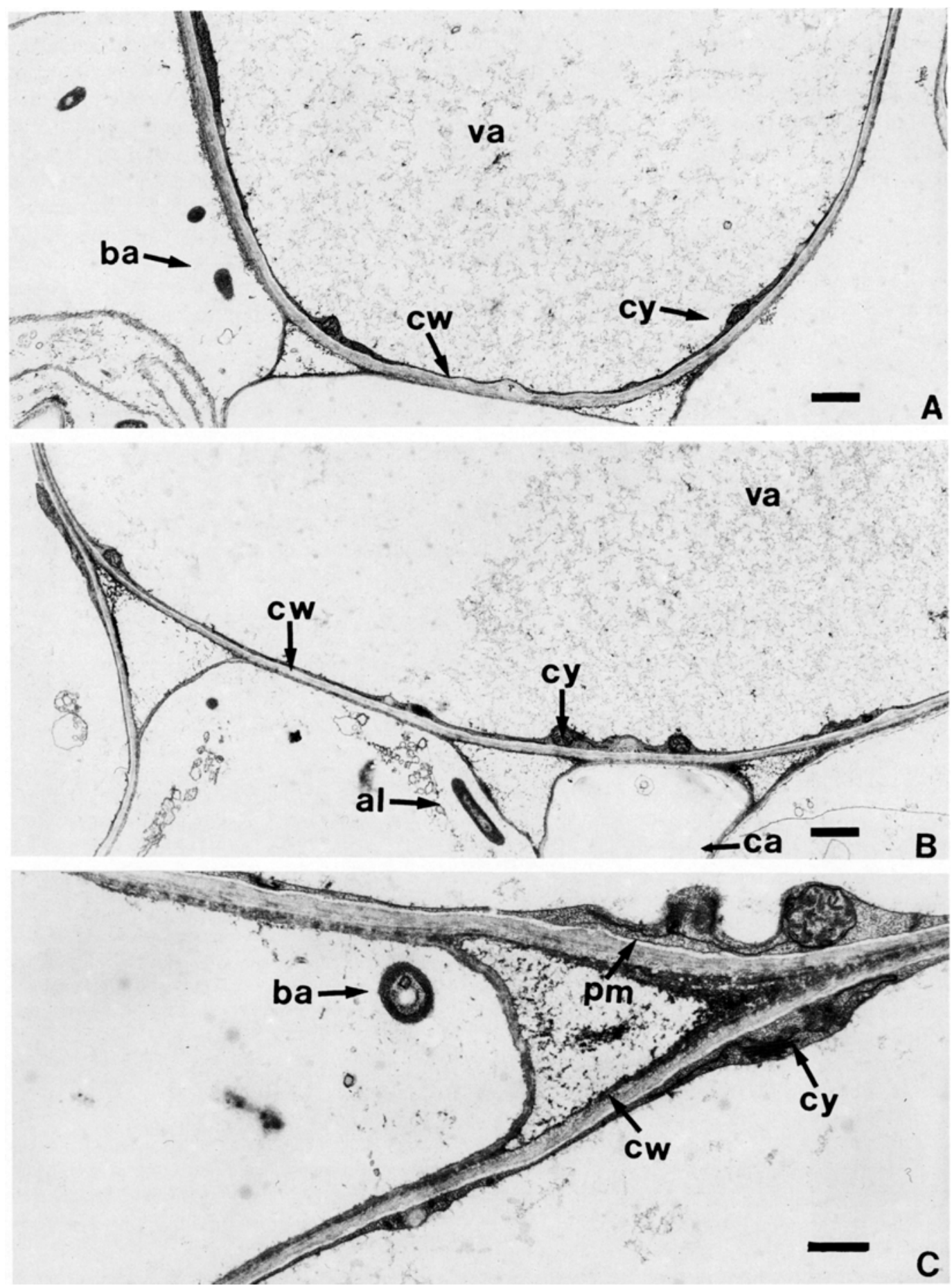

Fig. 9A-C. Parts of rhizodermal cells of the iron-deficient RM 57 root depicted in Fig. 7. The rhizodermal cells are highly vacuolated (va) and the cytoplasm (cy) with an unfolded plasma membrane $(p m)$ is attached to the cell walls $(\mathrm{cw})$. Inbetween the remnants of the calyptra $(c a)$, bacteria $(b a)$ and green algae $(a l)$, which cannot be avoided in nutrient solutions, indicate the border between root and external medium. A, B $\times 7120$, C $\times 18280 ; \operatorname{bar}(\mathrm{s})=1 \mu \mathrm{m}$

ments of the in-vivo reductase activity and its biochemical properties have been published so far. In intact $A$. thaliana roots the $\mathrm{pH}$ optimum of FCR ( $\mathrm{pH} 5.0-5.5$ ) was similar to those for Arachis hypogeae (Römheld and Marschner 1983), Malus domestica (Ao et al. 1985) and Geum urbanum (Schmidt and Janiesch 1991). The $\mathrm{pH}$ optimum of Ficus benjamina was slightly higher, i.e. 5.5-6.7 (Rosenfield et al. 1991).

The $K_{\mathrm{m}}$ values of $45 \mu \mathrm{M}$ and $54 \mu \mathrm{M}$ Fe(III)-EDTA found for $A$. thaliana wild type and root hair-less mutant are practically identical to those determined for Arachis hypogeae ( $55 \mu \mathrm{M}$, Chaney 1989). For Phaseolus vulgaris (120 $\mu \mathrm{M}$, Bienfait 1988), Lycopersicon esculentum (230 $\mu \mathrm{M}$, Brüggemann et al. 1990) and Geum urbanum $(87 \mu \mathrm{M}$, Schmidt and Janiesch 1991) higher $K_{\mathrm{m}}$ values were found.

The root hair-less mutant did not develop transfer cells upon exposure to an iron-deficient medium and, with respect to root morphology, showed the same responses to an iron-free medium as the wild type, except for root-hair formation. The FCR activity of the two genotypes measured in different experiments (Table 1 and 
Fig. 2), showed that the reduction rates of the wild type always were approx. 2.5-fold higher than the rates of the mutant. Assuming that growth rates and demand for iron are the same for both genotypes it can be concluded that the root system of the wild type had more reaction sites for FCR activity than the mutant. Nevertheless, upon exposure to iron-deficient medium, the 4.2 -fold stimulation of FCR in the mutant, which did not show an increase of plasma-membrane surface by root hair formation (wild type), clearly indicates that induced FCR activity is not due to stimulation of root hair formation with its membrane enlargement but to enhanced expression and/or activation of the plasma-membrane-bound enzyme itself.

Evaluating the results of the present investigation, there are three reasons to conclude that the enhanced FCR activity induced by exposure of the roots to irondeficient solution and localized at the root elongation zone, is independent of the formation of root hairs or transfer cells: (i.) Upon iron deficiency, FCR activity was stimulated by the same order of magnitude in the root hair-less mutant as in the wild type. (ii.) In the wild type there was increased root hair formation by the second day of iron deficiency, but the highest FCR activity was found between days 5-7, when severe leaf chlorosis had developed. (iii) When $\mathrm{Fe}^{\mathrm{III}}$-EDTA was applied to the leaves, chlorosis and the morphological responses of lateral root growth to iron deficiency disappeared, while root FCR activity continued to be high. Clearly, the enhanced expression of FCR activity is not linked specifically to a differentiated morphological structure, but is located in the rhizodermal cells of the elongation and maturation zone behind the root tip. It is independent of the occurrence of root hairs and transfer cells.

In iron-deficient tomatoes, Chaney et al. (1992) observed increased root hair formation only after $5 \mathrm{~d}$ of iron deficiency, when severe chlorosis was already established. In contrast, in $A$. thaliana, increased root hair formation was seen after $24 \mathrm{~h}$ of iron deficiency, before chlorosis occurred. This time sequence of stress responses is in agreement with an earlier report (Bell et al. 1988) on the same tomato cultivar as used in the study of Chaney et al. (1992).

The number of laterals per root centimeter showed that, under iron deficiency the rigid and branched habit of the root system is a consequence of a decrease of distance between laterals without reduction in root length, as already described by Römheld and Marschner (1981). Application of ferric chelate to the leaves led to regreening of all leaves (independent of their age) and to normal distances between laterals, as seen in iron-sufficient control plants. The disappearance of the rigid root habit and the continued growth of laterals occurred together with the disappearence of chlorosis. This supports the idea that after foliar application either iron itself is transported to the root or another signal substance, which is only produced by the non-deficient shoot and which is responsible for lateral root length growth, is transported. For various reasons, induction of enhanced FCR activity did not disappear after regreening of the leaves. Either a change in FCR activity depends on a signal from the shoot, such as the iron-induced change in root morphology (i.e. iron content in the phloem sap). In this case, the trigger signal for return to normal FCR activity after iron application to the leaves was not strong enough for suppresion of enhanced root FCR activity, in contrast to the morphological root response. Alternatively, the root detected iron deficiency in the surrounding medium, and this signal regulated the induction of the "Turbo reductase" independently of any iron supply from the shoot. Both interpretations imply that there are at least two different detection systems in the plant for the iron status of the root: one for the morphological, and one for the physiological response.

Thanks are due to Klaas Sjollema (Department of Electronmicroscopy, University of Groningen, The Netherlands) for help with the electron microscopy sample preparation and especially to Dr. Uwe Santore (Heinrich-Heine-University) for electron microscopy. This work was supported by the SCIENCE programm of the European community; P.R.M.) and a Personal Research Grant by the Ministerium für Wissenschaft und Forschung of Nordrhein-Westfalen (P.R.M.) and last, not least by the productive discussions in ECOTRANS B.V.

\section{References}

Abadia, J. (1992) Leaf responses to Fe deficiency: A review. J. Plant Nutr. 15, 1699-1714

Ao, T.Y., Fan, F., Korcak, R.F., Faust, M. (1985) Iron reduction by apple roots. J. Plant Nutr. 8, 629-644

Bell, P.F., Chaney, R.L., Angle, J.S. (1988) Staining localization of ferric reduction on roots. J. Plant Nutr. 11, 1237-1252

Bienfait, H.F. (1987) Biochemical basis of iron efficiency reactions in plants. In: Iron transport in microbes, plants and animals, pp. 339-349, van der Helm, D., Neilands, J.B., Winkelmann, G., eds. Verlag Chemie, Weinheim

Bienfait, H.F. (1988) The Turbo reductase in plant plasma membranes. In: Plasma membrane oxidoreductases in control of animal and plant growth, pp. 89-98, Crane, F.L., Morré, D.J., Löw, H.E., eds. Plenum Press, New York

Brüggemann, W., Moog, P.R., Nakagawa, H., Janiesch, P., Kuiper, P.J.C. (1990) Plasma membrane-bound $\mathrm{Fe}^{3+}$-EDTA reductase and iron deficiency in tomato Lycopersicon esculentum. Is there a Turbo reductase? Physiol. Plant. 79, 339-346

Buckhout, T.J., Luster, D.G., Chaney, R.L. (1989) Iron-stress induced redox activity in tomato (Lycopersicon esculentum Mill.) is localized on the plasma membrane. Plant Physiol. 90, 151-156

Chaney, R.L. (1989) Kinetics of ferric chelate reduction by roots of iron-deficient peanut (Arachis hypogea). Acta Bot. Neerl. 38, 153-163

Chaney, R.L., Brown, J.D., Tiffin, L.O. (1972) Obligatory reduction of ferric chelates in iron uptake by soybeans. Plant Physiol. 50, 208-213

Chaney, R.L., Chen, Y., Green, C.E., Holden, M.J., Bell, P.F., Luster, D.G., Angle, J.S. (1992) Root hairs on chlorotic tomatoes are an effect of chlorosis rather than part of the adaptive Fe-stress response. J. Plant Nutr. 15, 1857-1875

Doddema, H. (1978) Uptake of nitrate by chlorate resistant mutants of Arabidopsis thaliana (L.) Heynh. Ph. D. thesis. University of Groningen, Groningen, Netherlands

Dolcet-Sanjuan, R., Mok, D.W.S., Mok, M.C. (1992) Characterization and in vitro selection for iron efficiency in Pyrus and $C y d o-$ nia. In Vitro Cell Dev. Biol. 28P, 25-29

Kramer, D., Römheld, V., Landsberg, E., Marschner, H. (1980) Induction of transfer cell formation by iron deficiency in the root epidermis of Helianthus annuus L. Planta 147, 335-339 
Landsberg, E.C. (1982) Transfer cell formation by iron deficiency in the root epidermis: a prereqisite for Fe efficiency? J. Plant Nutr. 5, 415-432

Landsberg, E.C. (1986) Function of rhizodermal transfer cells in Fe stress response mechanism of Capsicum annum L. Plant Physiol. 82, 511-517

Landsberg, E.C. (1989) Proton efflux and transfer cell formation as a responses to $\mathrm{Fe}$ deficiency of soybean in nutrient solution culture. Plant Soil 114, 53-61

Marschner, H., Römheld, V., Horst, W.J., Martin, P. (1986) Root-induced changes in the rhizosphere: Importance for the mineral nutrition of plants. Z. Pflanzenernähr. Bodenk. 149, 441-456

Misra, R.K., Alston, A.M., Dexter, A.R. (1988) Role of root hairs in phosphorus depletion from a macrostructured soil. Plant Soil 107, 11-18

Moog, P.R., Brüggemann, W. (1994) Iron reductase systems at the plant plasma membrane. Plant Soil 165 , in press

Moog, P.R., Janiesch, P. (1990) Root growth and morphology of Carex species as influenced by oxygen deficiency. Funct. Ecol. 4, 201-208

Reynolds, E. (1963) The use of lead citrate at high $\mathrm{pH}$ as an electronopaque stain in electron microscopy. J. Cell Biol. 17, 208212

Römheld, V. (1987) Existence of two different strategies for the acquisition of iron in higher plants. In: Iron transport in microbes, plants and animals, pp 353-374, van der Helm, D., Neilands, J.B., Winkelmann, G., eds. Verlag Chemie, Weinheim

Römheld, V., Kramer, D. (1983) Relationship between proton efflux and rhizodermal transfer cells induced by iron deficiency. $\mathrm{Z}$. Pflanzenphysiol. 113, 73-83

Römheld, V., Marschner, H. (1981) Iron deficiency stress induced morphological and physiological changes in root tips of sunflower. Physiol. Plant. 53, 354-360

Römheld, V., Marschner, H. (1983) Mechanism of iron uptake by peanut plants I. FeIII reduction, chelate splitting and release of phenolics. Plant Physiol. 71, 949-954

Rosenfield, C.L., Reed, D.W., Kent, M.W. (1991) Dependency of iron reduction on development of a unique root morphology in Ficus benjamina L. Plant Physiol. 95, 1120-1124

Schiefelbein, J.W., Somerville, C. (1990) Genetic control of root hair development in Arabidopsis thaliana. Plant Cell 2, 235-243

Schmidt, W., Janiesch, P. (1991) Ferric reduction by Geum urbanum: A kinetic study. J. Plant Nutr. 14, 1023-1034

Schmidt, W., Janiesch, P., Brüggemann, W. (1990) FeEDTA reduction in roots of Plantago lanceolata by a NADH-dependent plasma membrane-bound redox system. J. Plant Physiol. 136, $51-55$

Sijmons, P.C., Bienfait, H.F. (1983) Source of electrons for extracellular Fe(III) reduction in iron-deficient bean roots. Physiol. Plant. 59, 409-415 